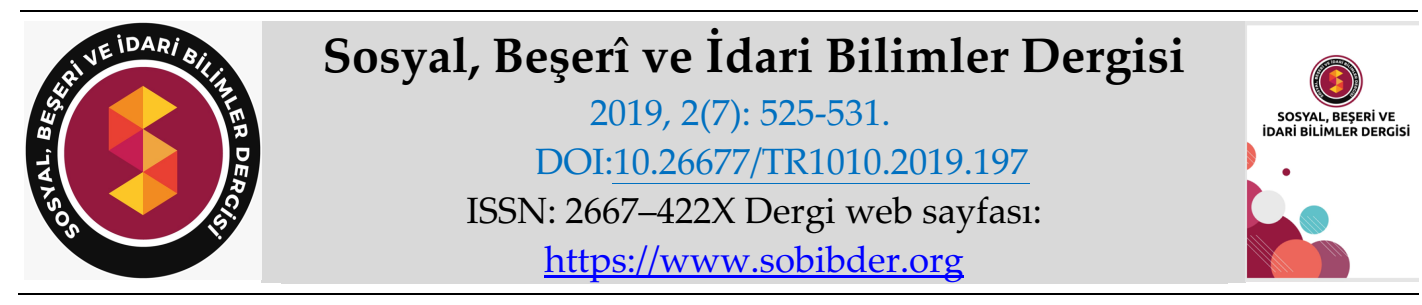

ARAŞTIRMA MAKALESI

\title{
Üniversite Öğrencilerinin Algıladıkları Stres Düzeyleri ile Duygusal Zeka Düzeyleri Arasındaki İlişkinin İncelenmesi
}

Dr. Öğr. Üyesi İrem ANLI, Demiroğlu Bilim Üniversitesi, Fen Edebiyat Fakültesi, Psikoloji Bölümü, İstanbul, e-posta:iremanli@superonline.com

ORCID: https://orcid.org/0000-0001-5630-2460

Psk. Merve Cansu KARADAĞ, e-posta: mervecansukaradag@gmail.com

ORCID: https://orcid.org/0000-0002-5797-985X

Psk. Ayşe ERTEN, e-posta: ayseertenn@hotmail.com

ORCID: https://orcid.org/0000-0002-2028-3429

Psk. Melike KARAKAYA, e-posta: melike.karakaya.14@gmail.com

ORCID: https://orcid.org/0000-0002-8100-7823

Öz

$\mathrm{Bu}$ araştırmanın amacı; üniversite öğrencilerinin algıladıkları stres düzeyleri ile duygusal zeka düzeyleri arasındaki ilişkiyi incelemektir. Araştırma Demiroğlu Bilim Üniversitesi'nde toplam 150 öğrenci ile yapılmıştır. Veri toplama araçları; Bar-On Duygusal Zeka Testi, Algılanan Stres Ölçeği (ASÖ) ve araştırmacılar tarafından oluşturulan Sosyodemografik Veri Formudur. Algılanan stres düzeyi ile duygusal zeka arasında istatistiksel açıdan anlamlı negatif yönde bir ilişki bulunmuştur.

Anahtar Kelimeler: Stres, Algilanan Stres, Duygusal Zeka.

Makale Gönderme Tarihi: 08.06.2019

Makale Kabul Tarihi: 24.07.2019

\section{Önerilen Atıf:}

Anlı, İ., Karadağ, M. C., Erten, A. ve Karakaya, M. (2019). Üniversite Öğrencilerinin Algıladıkları Stres Düzeyleri ile Duygusal Zeka Düzeyleri Arasındaki İlişkinin İncelenmesi, Sosyal, Beşeri ve İdari Bilimler Dergisi, 2(7): 525-531.

(c) 2019 Sosyal, Beşerî ve İdari Bilimler Dergisi. 


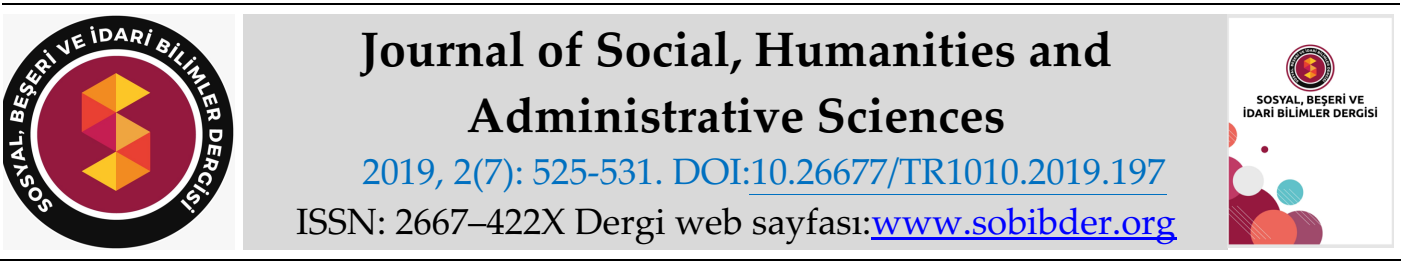

\title{
RESEARCH PAPER
}

\section{Investigation of the Relationship between Perceived Stress Levels and Emotional Intelligence Levels of University Students}

Assistant Prof. Dr. İrem ANLI, Demiroğlu Bilim University, Faculty of Arts and Sciences, Department of Psychology, İstanbul, e-mail:iremanli@superonline.com ORCID: https://orcid.org/0000-0001-5630-2460

Psychologist Merve Cansu KARADAĞ, e-mail: mervecansukaradag@gmail.com ORCID: https://orcid.org/0000-0002-5797-985X

Psychologist Ayşe ERTEN, e-mail: ayseertenn@hotmail.com

ORCID: https://orcid.org/0000-0002-2028-3429

Psychologist Melike KARAKAYA, e-mail: melike.karakaya.14@gmail.com

ORCID: https://orcid.org/0000-0002-8100-7823

\begin{abstract}
The aim of this study was to investigate the relationship between perceived stress levels and emotional intelligence levels of university students. The research was accomplished by 150 students in Demiroglu Bilim University. Bar-On Emotional Intelligence Test, Perceived Stress Scale (PSS) and Demographic Information Form which was created by the researchers were used to collect data. It was founded that there was a statistically significant negative relationship between perceived stress level and emotional intelligence.
\end{abstract}

Keywords: Stress, Perceived Stress, Emotional Intelligence

Received: 08.06.2019

Accepted: 24.07.2019

\section{Suggested Citation:}

Anlı, İ., Karadağ, M. C., Erten, A. and Karakaya, M. (2019). Investigation of the Relationship between Perceived Stress Levels and Emotional Intelligence Levels of University Students, Journal of Social, Humanities and Administrative Sciences, 2(7): 525-531.

(c) 2019 Sosyal, Beşerî ve İdari Bilimler Dergisi. 


\section{GİRIŞ}

Stres günlük hayatta pek çok insanın karşılaşmakta olduğu, kişiyi psikolojik ve fiziksel açıdan zorlayan bir durumdur. Stres ile ilgili pek çok tanımlama bulunmaktadır. Lazarus, stresi kişinin davranışlarını etkileyen rahatsız edici bir sonuç yaratan olay olarak tanımlamıştır (Aytaç, 2002). 1956 yılında Selye, stresin birçok tanımı olduğu için "ne olmadığını" belirtmenin daha uygun olduğunu ifade etmiş ve stresin sadece sinirsel gerginlikle ortaya çıkan bir hasar olmadığını, normal aktivitelerin de stresi ortaya çıarabileceğini belirtmiştir (Doğan ve Eser, 2013).

Stres durumunum ilk aşaması olan alarm evresi, stresi ortaya çıkaran durumun algılanması ve canlının bedensel tepkilerle kendini savunmaya çalıştığı evredir. İkinci aşama olan direnme evresi, canlının karşı karşıya olduğu stres yaratan duruma direncini arttırdığı evredir. Üçüncü evre olan tükenme evresi, stresle başa çıkılamayan durumlarda stresi oluşturan kaynakların artmasıyla bedenin uyum potansiyelinin zorlanma yaşadığı evredir. Buna göre, kişilerin stresle karşılaştıkları durumda stresi nasıl algıladıkları son derece önemli role sahiptir. Stresin artıp azalmasında kişilerin yaşadıkları olayları algılayışı ve değerlendirişi temel noktadır. Aynı sosyal ya da fiziki ortamlarda olan kişilerin bazıları kendini baskı altında hissedip bundan rahatsızlık duyarken, bazıları bundan rahatsızlık duymayabilir (Cüceloğlu, 1991).

İnsanlar yaşamları boyunca farklı dönemlerden geçerler. Her dönem kendi içinde pek çok özellik barındırır. Bu dönemlerin içerisindeki gençlik dönemi, insanların yaşantılarına yön verdikleri, sosyal ve fiziksel açıdan değişim içinde oldukları bir dönemdir. Bu dönemde üniversitede okuyan gençlerin psikolojik sağlıkları, toplum sağlığının önemli unsurudur (Kaya ve ark, 2007).

Öğrenciler üzerinde stres yaratan durumlar; uyum, akademik ve sosyal sorunlardır (Dyson ve Renk, 2006). Öğrenciler bu sorunları algılama düzeylerine göre çeşitli şekillerde sorunlarla uğraşırlar. Bireylerin yaşadıkları sorunlar karşısında ne hissettiklerini fark edip, olayı ve duygularını doğru anlayabilmeleri stres düzeyleri açısından önemli bir husustur.

John D. Mayer ve Peter Salovey ilk defa 1997 yılında duygusal zekayı, duyguları algılayabilme düşünceye yardım edebilmek için duyguları oluşturma, duyguları anlama, duygusal ve fikirsel olarak gelişim elde edebilmek için duyguları mantıksal olarak düzenleyebilme yeteneği olarak tanımlamıştır (Mayer ve Salovey, 1997).

Duyguların doğru anlaşılması duygusal zeka yeteneğini gerektirir. Duygusal zeka en genel anlamıla kişinin etrafındaki bireyleri ve kendisini anlama, çevreyle iyi ilişkiler içinde olma, oluşan beklenmedik durumlarda uyum gösterebilme ve problemlerle başa çıabilme becerisi olarak ifade edilir (Gürbüz ve Yüksel, 2008).

Duygusal zeka ayrıca "kendini harekete geçirebilme, aksiliklere rağmen yola devam edebilme, dürtüleri kontrol ederek doyumu erteleyebilme, ruh halini düzenleyebilme, sıkıntıların düşünmeyi engellemesine izin vermeme, kendini başkalarının yerine koyabilme ve umut besleme" yetenekleri şeklinde tanımlanmaktadır (Goleman, 2010).

Duygusal zekayı açılamak üzere çeşitli modeller oluşturulmuştur. Bu modellerin içinde Bar-On Karma modeli, kişilerin duygusal durumdan bakıldığında neden bazılarının daha iyi durumda olduğunu ve bazılarının yaşamlarında diğerlerinden daha başarılı olduğunu anlamaya çalıştığı ve bu nedenle karma olarak isimlendirilen, Dr. Reuven Bar-On tarafından ileri sürülmüşs olan bir modeldir (Goleman, 2000).

Bar-On duygusal zeka ile ilgili çalışmalarına 1980'li yıllarda başlamıştır. Bu modelin gelişim aşamasında Darwin'in yaşama uyum sağlamak ve hayatta kalmak için duyguları ifade etmenin son derece önemli olduğu noktasından etkilenmiştir. Bar-On duygusal zeka tanımlanırken "duygusal katsayı" terimini ilk kez kullanan kişi olmuştur. Bar-On'un duygusal zeka modeli, duygusal zekayla birlikte sosyal zeka modelini de içermektedir (Çakar ve Arbak, 2004). Bar-On' un temel olarak 
üzerinde durduğu durum, zihinsel olmayan zeka faktörleridir. Bunlar zekanın kişisel, duygusal, sosyal ve hayatta kalma boyutlarını içerir. Duygusal zeka, bireylerin günlük yaşamla baş edebilmesi için akademik zekadan daha önemlidir (Çakar, 2002).

Duygusal zeka yeteneği, sosyal yetenek, sosyal davranış ve sosyal olma özelliklerinden oluşmaktadır. $\mathrm{Bu}$ modelde anlatılmak istenen duyguların, kişilerin her alandaki başarılarında rol belirlemesidir. Duygusal zeka, kişinin kendisini ve kendisi dışındakini anlamasını, diğerleriyle ilişki kurmasını ve içinde bulunduğu her ana uyum sağlayıp o an içindeki olaylarla baş edebilmesini sağlayan özelliklerden oluşur ve ayrıca bunlar sayesinde birey, bulunduğu çevreye uyum gücünü arttırır (K1liçarslan, 2009).

Bu bağlamda değerlendirildiğinde duygusal zekanın, algılanan stres seviyesini ve stresle başa çıkmayı etkilediği öngörülmektedir.

\section{METOD}

Çalışmada; 150 üniversite öğrencisine Sosyo-demografik Veri Formu, Algılanan Stres Ölçeği ve BarOn Duygusal Zeka Ölçeği uygulanmış ve algılanan stres düzeyi ile duygusal zeka arasındaki ilişki araştırılmıştır.

\section{ÖRNEKLEM}

Araştırmanın örneklemini 2018-2019 eğitim-öğretim yılı bahar döneminde Demiroğlu Bilim Üniversitesi Fen-Edebiyat Fakültesi'nde öğrenim gören, sosyo-demografik özellikler açısından homojen olan 150 öğrenci oluşturmaktadır.

\section{VERI TOPLAMA ARAÇLARI}

SOSYODEMOGRAFIK VERI FORMU: Araştırmacılar tarafından oluşturulan formda katılımcıların kişisel bilgileri yer almaktadır. Bunlar; yaş, cinsiyet, fakülte ve bölüm, ekonomik düzey (alt, orta, üst), yaşadığı şehir, kaldığı yer (yurt, ev) ve şehir dışından gelmiş olup olmama bilgilerini belirlemek adına sorulan sorulardır. Çalışma grubunu homojen tutmak amacıyla kullanılmıştır.

ALGILANAN STRES ÖLÇEĞİ: Bireyin hayatındaki bazı durumların ne kadar stresli algılandığını ölçmek için tasarlanan Algılanan Stres Ölçeği (ASÖ), Cohen, Kamarck ve Mermelstein tarafından 1983 yılında geliştirilmiştir. Ölçeğin geçerlik güvenirlik çalışması, Eskin ve arkadaşları tarafından yapılmıştır (Eskin vd., 2013). Ölçek toplam 14 maddeden oluşmaktadır. Katılımcılar her maddenin değerlendirmesini "Hiçbir zaman (0)" ve "Çok sık (4)" arasında değişen 5'li Likert tipi ölçek üzerinde yapmaktadır. Maddelerden 7 tanesi $(4,5,6,7,9,10,13$. maddeler) olumlu ifade içerir ve bu maddeler tersten puanlanır. Ölçekten alınabilecek puanlar 0-56 arasında değişmektedir. Alınan yüksek puan, kişinin stres algısının fazlalığını belirtmektedir.

BAR-ON DUYGUSAL ZEKA ÖLÇEĞİ: Araştırmada duygusal zeka düzeyini belirlemek için, BarOn (1997) tarafından geliştirilen ve Acar (2001) tarafından Türkçe'ye uyarlama çalışmaları yapılan 
Bar-On Duygusal Zekâ Ölçeği kullanılmıştır. Ölçekteki maddelerden bazı maddeler ters yönde değerlendirilen maddelerdir. Bu maddeler; 3, 6, 9, 11, 12, 13, 16, 17, 21, 22, 24, 29, 35-38, 39, 41, 44, 47, 51, 56, 58, 59, 60, 64-67, 70, 71, 73, 77, 79, 80, 82, 83, 85 ve 86. maddelerdir (Acar, 2001).

Katılımcılar her maddenin değerlendirmesini "Tamamen katılıyorum (1)" ile "Kesinlikle katılmıyorum (5)" arasında değişen 5'li Likert tipi ölçek üzerinde yapmaktadır. Ölçek 88 madde ve 5 alt boyuttan oluşmaktadır. Ölçeğin alt boyutları; kişisel beceriler, kişilerarası beceriler, uyumluluk boyutu, stresle başa çıkma boyutu ve genel ruh durumu boyutudur. Ölçek bu boyutlarla ilgili 87 madde ve bir kontrol ifadesinden (88. madde) oluşmaktadır (Bar-On, 1999).

\section{İSTATİSTIKKSEL METOD}

Algılanan stres düzeyi ile duygusal zeka düzeyi arasındaki ilişkinin incelenmesi için Pearson Korelasyon Analizi kullanılmıştır.

\section{BULGULAR}

Tablo 1'de öğrencilerin Algılanan stres düzeyi puanları ile duygusal zeka düzeyi puanları arasındaki korelasyon görülmektedir. Algılanan stres düzeyi ile duygusal zeka düzeyleri arasında 0.01 düzeyinde negatif yönde anlamlı bir ilişki görülmektedir.

Tablo 1. Duygusal Zeka ile Algllanan Stres Düzeyinin Korelasyonel Sonucu

\begin{tabular}{|c|c|c|c|}
\hline \multicolumn{4}{|l|}{ Korelasyonlar } \\
\hline & & Duygusal Zeka & Algılanan Stres \\
\hline \multirow[t]{3}{*}{ Duygusal Zeka } & $\begin{array}{l}\text { Pearson Korelasyon } \\
\text { Katsayıs1 }\end{array}$ & 1 &,$- 401^{* *}$ \\
\hline & $p$ & & ,000 \\
\hline & $\mathbf{N}$ & 108 & 108 \\
\hline \multirow[t]{3}{*}{ Algılanan Stres } & $\begin{array}{l}\text { Pearson Korelasyon } \\
\text { Katsayıs1 }\end{array}$ &,$- 401^{* *}$ & 1 \\
\hline & $\mathrm{p}$ & ,000 & \\
\hline & $\mathbf{N}$ & 108 & 108 \\
\hline
\end{tabular}

\section{TARTIŞMA}

Duygusal zeka ve algılanan stres günümüzde giderek önem kazanmış konulardandır. Stres günlük hayatın parçası halini almıştır, şöyle ki; günümüzde insanlar karşılaştıkları stresli durumların farkında olmasa da yoğun stres altındadır. Kişi var olan stresli olayı kendi zihinsel yapısına göre algılar. Bu yüzden stres yaratan olaydan çok kişinin stresi nasıl algıladığı son derece önemlidir (Cohen vd., 1983). 
Duygusal zeka bireylerin davranışlarının temeline ve stresli durumlarda bireyin daha sağlıklı kararlar alabilmesi ve yönlendirilmesi gibi durumlara etki eder. Duygusal zeka, kişinin duygularını anlayıp yönlendirebilme yeteneğidir. Bu yeteneğe sahip kişiler kendini tanıyıp yaşadıkları olaylara uygun duygusal tepkiler vermektedirler (Kılıçarslan, 2009).

İnsan hayatının pek çok zorlu dönemi içinde üniversite zamanı birçok stres faktörünün bir arada bulunduğu bir dönemdir. Bu durum göz önüne alınarak, araştırmada üniversite öğrencilerinin algıladıkları stres düzeyi ile duygusal zeka düzeyleri arasındaki ilişkinin incelenmiştir. Çalışmada öğrencilerin algıladıkları stres düzeyleri ile duygusal zeka düzeyleri arasında negatif yönde anlamlı bir ilişki saptanmıştır. Araştırma hipotezi bulgular ışığında doğrulanmıştır. Kişinin duygusal zekasının yüksek olması, çevresiyle uyumlu ilişkiler geliştirmesini sağlamaktadır. Bu durum da algılanan stres düzeyini düşürmektedir.

Literatür incelemesinde üniversite öğrencilerinin algıladıkları stres düzeyleri ile duygusal zeka düzeyleri arasındaki ilişkinin incelenmesi üzerine güncel çalışmaların bulunmadığı görülmüştür. Bu yüzden bu araştırmanın bu konu için temel teşkil edeceği düşünülmektedir.

Çalışmanın bazı sınırlılıkları bulunmaktadır. Bu sınırlılıklardan biri, çalışmaya bir üniversitenin, tek bir kampüs sınırları içerisindeki öğrencilerin katılmış olmasıdır. Farklı kampüslerden veri toplanabilmesi sayesinde pek çok farklı bölümden öğrencinin stres puanlarının, bölümlere göre farklılığına bakılabilir. Çalışma verilerinin bir vakıf üniversiteden toplanmış olması öğrencilerin benzer sosyo-demografik özelliklere sahip olmasına yol açmış olabilir. Konuyla ilgili yapılacak olan diğer çalışmaların hem devlet hem de vakıf üniversite öğrencilerinden bir arada toplanması önerilmektedir. Böylece çalışmaya çok farklı sosyo-demografik özelliklere sahip üniversite öğrencilerinin katılımı sağlanmış olur. Böylece stresi etkileyen farklı durumların göz önünde bulundurulması sağlanmış olacaktır. Çalışmada kullanılan Bar-on EQ Testinin uzun olması sebebiyle katılımcların sıkıldığı ve bazı katılımcıların anketi bitirmek için ilgilenmeden cevap verdikleri görülmüştür. Yapılacak yeni çalışmalarda Bar-On EQ Testinin kısa formunun kullanılması önerilmektedir.

\section{KAYNAKÇA}

Acar, F.T. (2001). Duygusal Zeka Yeteneklerinin Göreve Yönelik ve İnsana Yönelik Liderlik Davranışları ile İlişkisi: Banka Şube Müdürleri Üzerine bir Alan Araştırması. Doktora Tezi. İstanbul Üniversitesi, İstanbul.

Aytaç, S. (2002). İş Yerindeki Stres Kaynakları. İşgüç Endüstri İlişkileri ve İnsan Kaynakları Dergisi. Cilt. 4. Sayı: 1.

Bar-On, R., (1999). EQ-i BarOn Emotional Quoitent Inventory: Technical Manual. Multi-Health Systems, Toronto.

Bar-On, R., (1997). Development of the BarOn EQ-i: A Measure of Emotional and Social Intelligence, Amerikan Psikologlar Birliği 105. Yıl Toplantısı Sunumu, Chicago.

Cohen, S, Kamarck, T. and Mermelstein R. (1983). A Global Measure of Perceived Stress. Journal of Health and Social Behavior; 24: 385-396

Cüceloğlu, D. (1991). İnsan ve Davranışı. İstanbul: Remzi Kitabevi.

Çakar, U. (2002). Duygusal Zekanın Dönüşümcü Liderlik Davranışı Üzerindeki Etkisi. Yüksek Lisans Tezi. Dokuz Eylül üniversitesi, İzmir.

Çakar, U. ve Arbak, Y. (2004). Modern Yaklaşımlar Işı̆̆ında Değişen Duygu Zeka İlişkisi ve Duygusal Zeka. D.Ü. Sosyal Bilimler Enstitüsü Dergisi, 6(3), 23-48. 
Doğan, B., ve Eser, M. (2013). Üniversite Öğrencilerinin Stresle Başa Çıkma Yöntemleri: Nazilli MYO Örneği. Ejovoc (Electronic Journal of Vocational Colleges), 3(4).

Dyson, R., and Renk, K. (2006). Freshmen Adaptation to University Life: Depressive Symptoms, Stress, and Coping. Journal of Clinical Psychology, 62(10), 1231-1244.

Eskin, M., Harlak, H., Demirkıran, F. ve Dereboy, Ç., (2013). Algılanan Stres Ölçeğinin Türkçeye Uyarlanması: Güvenilirlik ve Geçerlik Analizi, New Symposium Journal, 51/3: 132-140

Goleman, D. (2010). Duygusal Zeka Neden IQ’ dan Daha Önemlidir? 33. Baskı, İstanbul: Varlık Yayınları.

Goleman, D. (2000). İş Başında Duygusal Zeka. İstanbul:Varlık Yayınları.

Gürbüz, S. ve Yüksel, M. (2008). Çalışma Ortamında Duygusal Zeka: İş Performansı, İş Tatmini, Örgütsel Vatandaşlık Davranışı ve Bazı Demografik Özelliklerle İlişkisi. Doğuş Üniversitesi Dergisi, 9(2), 174-190.

Kaya, M., Genç, M., Kaya, B. ve Pehlivan, E. (2007). Tıp Fakültesi ve Sağlık Yüksekokulu Öğrencilerinde Depresif Belirti Yaygınlığı, Stresle Başa Çıkma Tarzları ve Etkileyen Faktörler. Türk Psikiyatri Dergisi 2007, 18(2), 137-146.

Kılıçarslan, F. (2009). On Adımda Duygusal Zeka: Yaşamboyu Başarıyı Yakalamanın Sırları. İstanbul: Zen Yayınları.

Mayer, J. and Salovey, P. (1997). What is Emotional Intelligence? Emotional Development and Emotional Intelligence. New York: Basic Books. 